\title{
A distinct epigenetic signature at targets of a leukemia protein Stefano Rossetti ${ }^{1}$, André T Hoogeveen ${ }^{2}$, Ping Liang1, Cornel Stanciu1, Peter van der Spek ${ }^{3}$ and Nicoletta Sacchi*1
}

\author{
Address: ${ }^{1}$ Department of Cancer Genetics, Roswell Park Cancer Institute, Elm and Carlton Streets, Buffalo, NY 14263, USA, ${ }^{2}$ Department of \\ Clinical Genetics, Erasmus MC, Dr Molewaterplein 50, 3015GE Rotterdam, The Netherlands and ${ }^{3}$ Department of Bioinformatics, Erasmus MC, \\ Dr Molewaterplein 50, 3015GE Rotterdam, The Netherlands \\ Email: Stefano Rossetti - stefano.rossetti@roswellpark.org; André T Hoogeveen - a.hoogeveen@erasmusmc.nl; \\ Ping Liang - ping.liang@roswellpark.org; Cornel Stanciu - cornel.stanciu@utoronto.ca; Peter van der Spek - p.vanderspek@erasmusmc.nl; \\ Nicoletta Sacchi* - nicoletta.sacchi@roswellpark.org \\ * Corresponding author
}

Published: I February 2007

BMC Genomics 2007, 8:38 doi:10.1/86/147|-2/64-8-38
Received: 4 October 2006

Accepted: I February 2007

This article is available from: http://www.biomedcentral.com/I47/-2/64/8/38

(c) 2007 Rossetti et al; licensee BioMed Central Ltd.

This is an Open Access article distributed under the terms of the Creative Commons Attribution License (http://creativecommons.org/licenses/by/2.0), which permits unrestricted use, distribution, and reproduction in any medium, provided the original work is properly cited.

\begin{abstract}
Background: Human myelogenous leukemia characterized by either the non random $\mathrm{t}(8 ; 2 \mathrm{I})(\mathrm{q} 22$; $\mathrm{q} 22)$ or $\mathrm{t}(16 ; 21)(\mathrm{q} 24 ; \mathrm{q} 22)$ chromosome translocations differ for both their biological and clinical features. Some of these features could be consequent to differential epigenetic transcriptional deregulation at AMLI targets imposed by AMLI-MTG8 and AMLI-MTGI6, the fusion proteins deriving from the two translocations. Preliminary findings showing that these fusion proteins lead to transcriptional downregulation of AMLI targets, marked by repressive chromatin changes, would support this hypothesis. Here we show that combining conventional global gene expression arrays with the power of bioinformatic genomic survey of AMLI-consensus sequences is an effective strategy to identify AMLI targets whose transcription is epigenetically downregulated by the leukemia-associated AMLI-MTGI6 protein.
\end{abstract}

Results: We interrogated mouse gene expression microarrays with probes generated either from $32 \mathrm{D}$ cells infected with a retroviral vector carrying AMLI-MTGI6 and unable of granulocyte differentiation and proliferation in response to the granulocyte colony stimulating factor (G-CSF), or from 32D cells infected with the cognate empty vector. From the analysis of differential gene expression alone (using as criteria a p value $<0.0 \mathrm{I}$ and an absolute fold change $>3$ ), we were unable to conclude which of the 37 genes downregulated by AMLI-MTGI6 were, or not, direct AMLI targets. However, when we applied a bioinformatic approach to search for AMLI-consensus sequences in the $10 \mathrm{~Kb}$ around the gene transcription start sites, we closed on 17 potential direct AMLI targets. By focusing on the most significantly downregulated genes, we found that both the AMLI-consensus and the transcription start site chromatin regions were significantly marked by aberrant repressive histone tail changes. Further, the promoter of one of these genes, containing a CPG island, was aberrantly methylated.

Conclusion: This study shows that a leukemia-associated fusion protein can impose a distinct epigenetic repressive signature at specific sites in the genome. These findings strengthen the conclusion that leukemia-specific oncoproteins can induce non-random epigenetic changes. 


\section{Background}

Nuclear hormone receptors and transcription factors can regulate the transcription of their target genes by inducing chromatin changes. Paradigmatic are the retinoic acid receptor alpha $(\mathrm{RAR} \alpha)$ and the transcription factor core binding factor $(\mathrm{CBF})$, which regulate in this way the transcription of target genes involved in hematopoietic processes [1,2]. Differently from RAR $\alpha$, which epigenetically activates its targets by recruiting coactivator protein complexes with histone acetyl transferase (HAT) activity only when bound to retinoic acid, CBF can directly recruit HAT-containing complexes to activate its targets [3-6]. One of the two CBF subunits, CBF $\alpha$ or AML1, can bind target genes endowed with the AML1-consensus sequence TG(T/C)GGT via its N-terminal DNA-binding domain [7]. $A M L 1$, encoding a master hematopoietic transcription factor, is frequently affected by different chromosome translocations in leukemic cells [8]. Moreover, AML1 haploinsufficiency was found to be associated with familial platelet disorder, a condition predisposing to acute myeloid leukemia [9].

Two leukemia-associated chromosome translocations, the $\mathrm{t}(8 ; 21)(\mathrm{q} 22 ; \mathrm{q} 22)$ and the $\mathrm{t}(16 ; 21)(\mathrm{q} 24 ; \mathrm{q} 22)$, result in the fusion between the N-terminal region of AML1 and the Cterminal regions of two almost identical chromatin corepressors, MTG8 and MTG16, leading to the formation of AML1-MTG8 and AML1-MTG16, respectively [10-13]. Upon fusion with either MTG8 or MTG16, AML1 is converted from a transcriptional activator into a transcriptional repressor of AML1-targets. Specific MTG domains in the wild type, as well as in the MTG fusion proteins, can interact, directly or via other corepressors such as NCoR and Sin3A, with histone deacetylases (HDACs), thus creating a repressive chromatin state at AML1 target sites (reviewed in $[14,15]$ ). Repression at these sites is further enhanced by the formation of oligomers between the fusion proteins and wild-type MTG proteins [16-18].

Myeloid cell differentiation systems, such as the 32D mouse myeloid cell line, ectopically expressing either AML1-MTG8 or AML1-MTG16, were used as models to simulate some of the effects of these fusion proteins in myelogenesis and leukemogenesis. Both fusion proteins, when exogenously expressed in the 32D background, were shown to affect granulocytic differentiation and produce distinct effects on cell proliferation [19-21]. In a preliminary study, we found that AML1-MTG16, when exogenously expressed in 32D cells, can induce aberrant myeloid phenotypes in association with repressive modifications at the chromatin of the Colony stimulating factor 1 receptor (Csf1r), an AML1-target gene encoding the macrophage colony stimulating factor receptor [19]. Based on this finding, we hypothesize that the comparative epigenetic analysis of the changes induced by differ- ent AML1-MTG fusion proteins in an identical cell context (e.g. the 32D context) might provide a lead to elucidating the differences observed in leukemic cells carrying either one of the two proteins [8]. The objective of this study was to demonstrate whether AML1-MTG16 induces epigenetic changes at AML1-target genes in the 32D myeloid cell genome. Only by coupling global gene expression array analysis with a bioinformatic genomic survey for the AML1-consensus sequence, we were able to close onto AML1-targets downregulated by AML1-MTG16. AML1MTG16-induced transcriptional downregulation was marked by the acquisition of a distinct repressive chromatin signature.

\section{Results \\ Global gene expression array analysis of AML I-MTG I 6- expressing cells}

To study the molecular and biological consequences of AML1-MTG16 expression in a myeloid differentiation cell model, we previously developed, by infecting 32D mouse myeloblasts with retroviral particles carrying either the pLNCX2 vector containing the AML1-MTG16 cDNA or the cognate empty vector, stable independent clones expressing AML1-MTG16 (hereafter called A16 clones) and stable independent control clones (hereafter called "mock" clones), respectively (Figure 1A). Upon treatment with granulocyte colony stimulating factor (G-CSF), A16 clones do not undergo granulocytic differentiation and proliferate significantly less than mock clones (Figure 1B). Global gene expression analysis (setting the p-value at < 0.05 and the absolute fold change at $>1.5$ ) of a prototypic A16 clone and a prototypic mock clone grown either with interleukin 3 (IL-3) or G-CSF for 16 h, was combined with bioinformatic analysis of the proteins encoded by all the differentially expressed genes with the Ingenuity software (see Methods). This analysis clearly revealed a network comprising proteins critical for platelet function in A16 cells (see Additional file 1). The identification of this protein network strongly supports the biological data, indicating the occurrence of functional AML1 haploinsufficiency in A16 cells [9].

Further analysis of the gene expression data (setting the pvalue at $<0.01$ and the absolute fold change at $>3$ ) enabled us to identify 138 differentially expressed genes, of which 66 differentially expressed genes in cells grown with IL-3, 67 differentially expressed genes in cells grown with G-CSF, and 5 differentially expressed genes in both cells grown with IL-3 and G-CSF (Figure 1C, left, and Table 1 and Table 2). According to the Ingenuity software, the differentially expressed genes in A16 cells were mostly implicated in tumorigenesis, cell proliferation, and hematopoiesis (Figure 1C, right). Since from this analysis alone we were unable to conclude whether, or not, these genes were AML1-MTG16 direct targets, we devised a bio- 
A

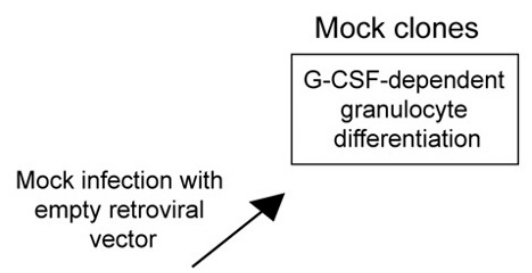

$32 \mathrm{D}$

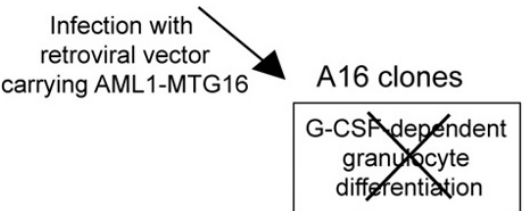

B

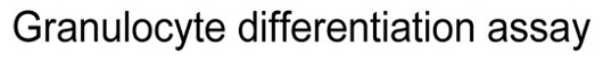

Proliferation assay
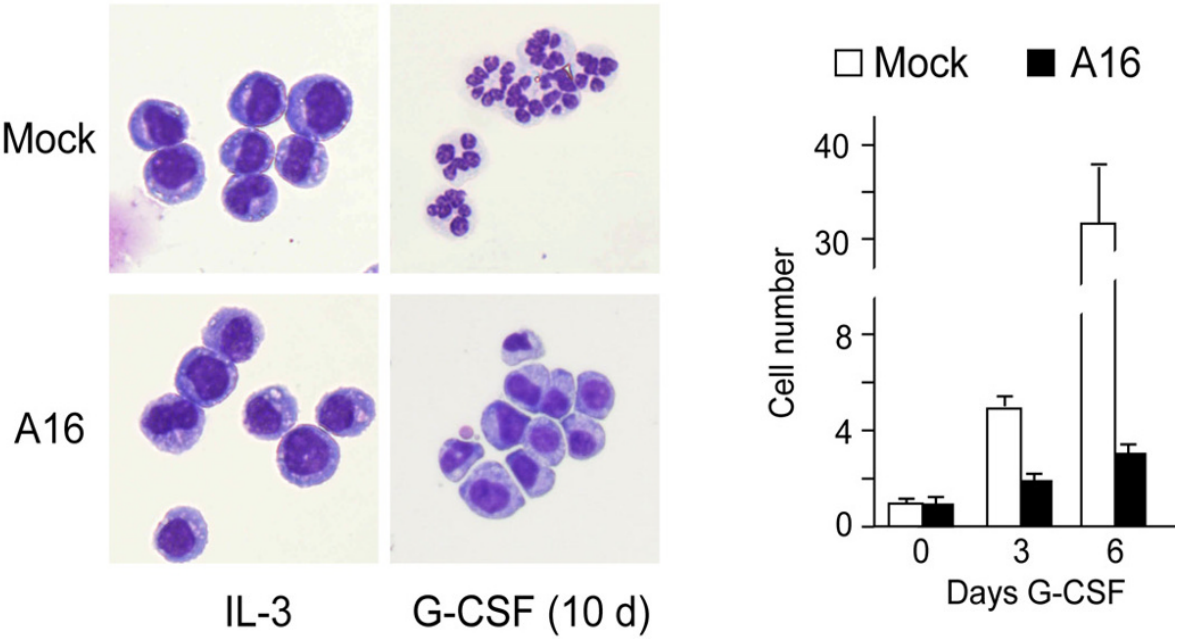

C

Gene selection: $p$-value $<0.01$ and absolute fold change $>3.0$

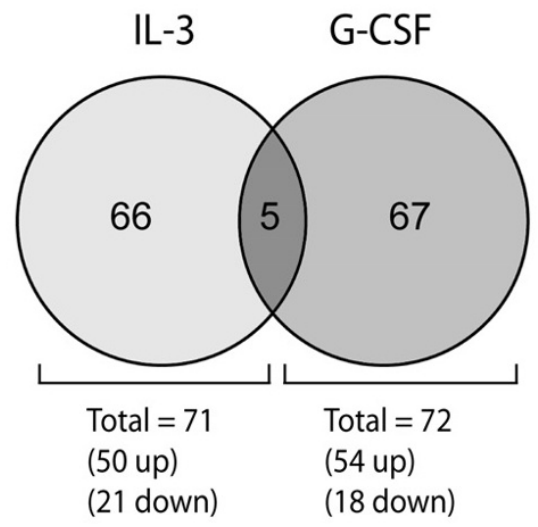

\begin{tabular}{lcc}
\hline Global function & Significance & N. of genes \\
\hline Tumorigenesis & $3.93 \mathrm{E}-4$ & 14 \\
$\begin{array}{l}\text { Cellular growth and proliferation } \\
\begin{array}{l}\text { Hematological system } \\
\text { development and function }\end{array}\end{array}$ & $3.93 \mathrm{E}-4$ & 20 \\
$\begin{array}{l}\text { Immune and lymphatic system } \\
\text { development and function }\end{array}$ & $5.36 \mathrm{E}-4$ & 11 \\
$\begin{array}{l}\text { Tissue morphology } \\
\text { Cell death }\end{array}$ & $5.36 \mathrm{E}-4$ & 12 \\
\hline
\end{tabular}

\section{Figure I}

Global gene expression analysis of AMLI-MTG 16-expressing cells. A. The 32D cell model, comprising clones expressing the AMLI-MTGI6 protein (AI6 clones) and control clones ("mock" clones), which do not express the fusion protein. B. A 16 clones, differently from mock clones, do not undergo granulocytic differentiation and display an impaired proliferation in the presence of G-CSF. C. Most of the genes whose expression is significantly affected in Al6 cells were found previously implicated in biological processes.

informatic approach aimed at identifying the AML1-consensus sequence in the $10 \mathrm{~Kb}$ region around the transcription start site of these genes.

\section{Identification of genes containing the AMLI-consensus sequence by bioinformatic analysis}

Since the AML1-MTG proteins have a transcriptionally repressive function (reviewed in [14]), we focused our bioinformatic analysis on the 37 genes downregulated by
AML1-MTG16 (see genes in bold in Table 1 and Table 2). Specifically, we searched the $10 \mathrm{~Kb}$ around the transcription start site of each gene for either the AML1-binding consensus sequence TG(T/C)GGT or, this sequence in reverse orientation, ACC (G/A)CA. With the MEME software (see Methods) we identified a conserved motif, hereafter called AML1-consensus motif (Figure 2A), encompassing the AML1-consensus sequence in seventeen out of the 37 genes (Figure $2 \mathrm{~B}$ and Table 3 ). We 
Table I: Selection of genes differentially expressed in AMLI-MTG I6-positive cells versus AMLI-MTG I6-negative cells grown in the presence of IL-3.

\begin{tabular}{lccc}
\hline Affymetrix ID & NCBI acc. number & Gene Symbol & Gene Title \\
\hline 1450042_at & BB32220I & Arx & aristaless related homeobox gene (Drosop \\
1460300_a_at & NM_008523 & leukocyte tyrosine kinase \\
1423869_s_at & AF349659 & Txnrd3 & thioredoxin reductase 3 \\
1418796_at & NM_009131 & Scgf & stem cell growth factor \\
1427329_a_at & Al326478 & Igh-6 & immunoglobulin heavy chain 6 (heavy chain of \\
1418588_at & NM_0095I3 & Vmp & vesicular membrain protein p24 \\
1450652_at & NM_007802 & Ctsk & cathepsin K \\
1428439_at & BG066220 & Nyren/8-pending & NY-REN-18 antigen \\
1419416_at & NM_011244 & Rarg & retinoic acid receptor, gamma
\end{tabular}

1419416_a_at NM_0II244 Rarg

1419136_at NM_134066

1425432 at AF260307

D30025I23Rik (Cbfb) RIKEN cDNA D330025123 gene (core-binding factor beta subunit)

Akrlcl 8

aldo-keto reductase family I, member $\mathrm{Cl} 8$

Oprm

Anxal0

NM_013754

1423029_at NM_008236 Hes2

454007 a_at AK020384

1423313 at $\quad$ BG070255 Pde7a

1451915_at L20509

1452487_x_at BBI33664

1422030_at AF326316

1427753_at

1437235_x_at

1426938_at

1460416_s_at

1427884_at

1450453_a_at

$1455957 \times$ at

1450215 at

1452489_at

1421705_at

1421375 a at

Z95479

BB2 18844

BB627486

M55219

AW550625

NM_012065

AV034167

NM_009038

BC016258

NM_018732

NM_0I I 3 I3

$1433658 \times$ AV300794

1418136_at NM_009365

AVII 4522

1450629_at

AW490145

BB522409

NM_00785

Al838010

BB800282

BC010807

452279

1419325_at

|422945_a_at

NM_019515

Al844677

NM_010815

1448529_at NM_009378

Pde7a
Cat3

Pirb

Atp6r0a4

lgh-4

Lpp

Noval

Csprs

Col3al

Pde6g

Ceacam II

Rcvrn

VpsII

$\operatorname{Sen} 3 a$

S100a6

Pcbp4

Tgfblil

Eplin-pending

Clon I

Gng2

Defcr5

Nell2

hairy and enhancer of split 2 (Drosophila)

zinc finger protein 142

phosphodiesterase 7A

chaperonin subunit 3 (gamma)

paired-lg-like receptor B

ATPase, $\mathrm{H}+$ transporting, lysosomal $\mathrm{V} 0$ subunit $\mathrm{A}$ isoform 4 immunoglobulin heavy chain 4 (serum lgGI)

LIM domain containing preferred translocation partner in lipoma neuro-oncological ventral antigen I

component of Spl00-rs

procollagen, type III, alpha I

phosphodiesterase 6G, cGMP-specific, rod, gamma

CEA-related cell adhesion molecule II

$$
\text { recoverin }
$$

vacuolar protein sorting II (yeast)

sodium channel, voltage-gated, type III, alpha polypeptide

SI00 calcium binding protein A6 (calcyclin) poly $(\mathrm{rC})$ binding protein 4

transforming growth factor beta I induced transcript I epithelial protein lost in neoplasm

$$
\text { chloride channel I }
$$

guanine nucleotide binding protein ( $G$ protein), gamma 2 subunit

defensin related cryptdin 5

nel-like 2 homolog (chicken)

properdin factor, complement

Tcea3

$\mathrm{Nmu}$

Kif5c

Mona

Thbd

kinesin family member $5 \mathrm{C}$

monocytic adaptor

thrombomodulin retinoic acid receptor, gamma

opioid receptor, mu

insulin-like 6

annexin AIO

GO/lngenuity annotations

regulation of transcription

nase signaling pathway

electron transport

cell adhesion/cell proliferation

immune response

$$
\text { proteolysis }
$$

regulation of transcription

regulation of transcription

electron transport

G-protein signaling pathway

physiological processes

regulation of transcription

electron transport

signal transduction

protein folding

ATP hydrolysis/proton transport immune response

cytoskeleton organization/transcriptional regulation mRNA splicing

G-protein signaling pathway cell adhesion

vision

---

protein transport

ion transport

cell proliferation

apoptosis

regulation of transcription$$
\text { --- }
$$

ion transport

G-protein signaling pathway defense response

cell adhesion

complement activation

regulation of transcription

neuropeptide signaling pathway

protein transport

tracellular signaling cascade blood coagulation 
$\infty$ Table I: Selection of genes differentially expressed in AMLI-MTG I6-positive cells versus AMLI-MTGI6-negative cells grown in the presence of IL-3. (Continued)

\begin{tabular}{|c|c|c|c|c|c|}
\hline 1449830_at & NM_013766 & Prlpi & prolactin-like protein I & --- & 3.2 \\
\hline |423596_at & BB52839I & Nek6 & NIMA (never in mitosis gene a)-related expressed kinase 6 & kinase signaling pathway/cell proliferation & 3.2 \\
\hline 1450435_at & NM_008478 & Slc7a2 & $\begin{array}{l}\text { solute carrier family } 7 \text { (cationic amino acid transporter, } y+\text { system), } \\
\text { member } 2\end{array}$ & amino acid transport & 3.2 \\
\hline |420373_at & $\mathrm{B} 1249549$ & Foxj2 & forkhead box J2 & regulation of transcription & 3.1 \\
\hline 1436769_at & AVIOIOII & Psmal & proteasome (prosome, macropain) subunit, alpha type I & ubiquitin-dependent protein catabolism & 3.1 \\
\hline |421778_at & NM_01191I & VIrb2 & vomeronasal I, receptor B2 & $\begin{array}{c}\text { chemosensory perception/G-protein signaling } \\
\text { pathway }\end{array}$ & 3.0 \\
\hline |4484|6_at & NM_008597 & Mglap & matrix gamma-carboxyglutamate (gla) protein & --- & -3.0 \\
\hline 1419012_at & NM_0I I 766 & Zfpm2 & zinc finger protein, multitype 2 & regulation of transcription & -3.0 \\
\hline |449833_at & NM_0I I 472 & Sprr2f & small proline-rich protein $2 F$ & --- & -3.1 \\
\hline |4248 |4_a_at & BC02554I & $\begin{array}{l}\text { 9030625MOIRik } \\
\text { (Bclg) }\end{array}$ & $\begin{array}{l}\text { RIKEN cDNA } 9030625 \mathrm{MOI} \text { gene (apoptosis regulator } \\
\text { Bclg) }\end{array}$ & apoptosis & -3.1 \\
\hline 1417338_at & U03487 & Epb4.2 & erythrocyte protein band 4.2 & structural function & -3.3 \\
\hline 1448|52_at & NM_0105 I 4 & $\operatorname{lgf2}$ & insulin-like growth factor 2 & cell proliferation & -3.6 \\
\hline 1429947_a_at & AK008I79 & Zbpl & Z-DNA binding protein I & --- & -3.7 \\
\hline |420394_s_at & U05264 & $G p 49 b$ & glycoprotein 49 B & immune response? & -3.7 \\
\hline 1424898_at & BC02II54 & Slcloal & $\begin{array}{l}\text { solute carrier family } 10 \text { (sodium/bile acid cotransporter } \\
\text { family), member I }\end{array}$ & ion transport & -3.8 \\
\hline 1416822_at & BCOI37II & Es2el & expressed sequence 2 embryonic lethal & --- & -4.0 \\
\hline 1419124_at & NM_I33829 & $A W 2 I 2394$ & expressed sequence AW2 12394 & --- & -4.4 \\
\hline 1425597_a_at & AW060288 & Qk & quaking & apoptosis & -4.6 \\
\hline |4224|6_s_at & NM_0I6983 & Vpreb2 & Pre-B lymphocyte gene 2 & hematopoiesis & -4.7 \\
\hline 1425863_a_at & AF295638 & Ptpro & protein tyrosine phosphatase, receptor type, 0 & phosphatase signaling pathway & -4.8 \\
\hline 1418177_at & AF233778 & Gabrg2 & $\begin{array}{l}\text { gamma-aminobutyric acid (GABA-A) receptor, subunit } \\
\text { gamma } 2\end{array}$ & synaptic transmission & -4.8 \\
\hline 1421309_at & NM_008598 & Mgmt & 0-6-methylguanine-DNA methyltransferase & DNA repair & -8.2 \\
\hline |42| 288_at & NM_007975 & F2rl3 & coagulation factor II (thrombin) receptor-like 3 & $\begin{array}{l}\text { blood coagulation/G-protein signaling } \\
\text { pathway }\end{array}$ & -14.2 \\
\hline |449347_a_at & NM_02I365 & XIr4 & X-linked lymphocyte-regulated 4 & chromatin remodeling? & -16.9 \\
\hline |4485 II_at & NM_016933 & Ptprcap & $\begin{array}{l}\text { protein tyrosine phosphatase, receptor type, C } \\
\text { polypeptide-associated protein }\end{array}$ & phosphatase signaling pathway & -17.7 \\
\hline 1421775_at & NM_010184 & Fcerla & Fc receptor, IgE, high affinity I, alpha polypeptide & signal transduction & -27.2 \\
\hline
\end{tabular}

Limits: $\mathrm{p}$-value $<0.0 \mathrm{I}$; absolute fold change $>3$.

In bold are the AMLI-MTGI6-downregulated genes searched for AMLI-consensus motifs. 
$\stackrel{\infty}{\infty}_{\infty}^{\infty}$ Table 2: Selection of genes differentially expressed in AMLI-MTG 16-positive cells versus AMLI-MTG I6-negative cells grown in the presence of G-CSF for 16 h.

\begin{tabular}{|c|c|c|c|c|c|}
\hline Affymetrix ID & NCBI acc. number & Gene Symbol & Gene Title & GO/lingenuity annotations & Fold change \\
\hline 1437100_x_at & BB206220 & Pim 3 & proviral integration site 3 & kinase signaling pathway & 24.5 \\
\hline 1460300_a_at & NM_008523 & Ltk & leukocyte tyrosine kinase & kinase signaling pathway & 19.9 \\
\hline 1416257_at & NM_009794 & Capn2 & calpain 2 & proteolysis/cell migration & 17.7 \\
\hline 1417314_at & NM_008198 & $\mathrm{H} 2-\mathrm{Bf}$ & histocompatibility 2, complement component factor B & cell proliferation/complement activation & 14.7 \\
\hline 1425380_at & $\mathrm{AF} 33 \mathrm{I} 457$ & Rasgrp4 & RAS guanyl releasing protein 4 & intracellular signaling cascade & 10.4 \\
\hline 1450322_s_at & NM_011409 & SIfn3 & schlafen 3 & cell proliferation & 10.2 \\
\hline 1421793_at & NM_010198 & FgflI & fibroblast growth factor II & signal transduction/cell proliferation & 9.5 \\
\hline 1420348_at & NM_008499 & $\operatorname{Lh} \times 5$ & LIM homeobox protein 5 & regulation of transcription & 8.8 \\
\hline 1419605_at & NM_010796 & $M g l l$ & macrophage galactose $\mathrm{N}$-acetyl-galactosamine specific lectin I & cell adhesion & 8.6 \\
\hline 1420360_at & NM_01005I & Dkkl & dickkopf homolog I (Xenopus laevis) & signal transduction/apoptosis & 6.7 \\
\hline 1425647_at & BG069740 & Rnf33 & ring finger protein 33 & --- & 6.4 \\
\hline |43485I_s_at & $A \cup 015319$ & Crb3 & crumbs homolog 3 (Drosophila) & intercellular junction assembly & 6.1 \\
\hline 1427|102_at & AF099975 & SIfn 4 & schlafen 4 & cell proliferation & 5.9 \\
\hline 1437218_at & BM234360 & $\mathrm{Fnl}$ & fibronectin I & cell adhesion & 5.5 \\
\hline 1417777_at & $\mathrm{BC} 014865$ & Ltb4dh & leukotriene B4 I2-hydroxydehydrogenase & metabolism & 5.5 \\
\hline 1419406_a_at & NM_016707 & Bcll la & B-cell CLL/lymphoma IIA (zinc finger protein) & T/B-cell differentiation/corepressor & 5.5 \\
\hline 1418358_at & NM_008574 & Mcsp & mitochondrial capsule selenoprotein & sperm motility & 5.4 \\
\hline 1450499_at & NM_009124 & Scal & spinocerebellar ataxia I homolog (human) & --- & 5.2 \\
\hline |4|8257_at & BB7̄32135 & SIc/2a7 & solute carrier family 12 , member 7 & ion transport & 5.1 \\
\hline 1424744_at & $\mathrm{BC} 021950$ & Sds & serine dehydratase & amino acid metabolism & 5.1 \\
\hline 1456305_x_at & BB702568 & Oboxl & oocyte specific homeobox I & regulation of transcription & 5.0 \\
\hline |449707_at & C80272 & $\mathrm{Nr} 5 a 2$ & nuclear receptor subfamily 5 , group $A$, member 2 & regulation of transcription & 4.9 \\
\hline |42|504_at & NM_009239 & Sp4 & trans-acting transcription factor 4 & regulation of transcription & 4.8 \\
\hline 1427079_at & U51204 & Mapre3 & microtubule-associated protein, RP/EB family, member 3 & cytoskeleton organization & 4.8 \\
\hline 1429626_at & AV02430I & Sftpa & surfactant associated protein $A^{\prime}$ & cell adhesion & 4.8 \\
\hline 1452793_at & Al5090II & Cldn 10 & claudin 10 & cell adhesion & 4.7 \\
\hline 1419507_at & NM_013713 & Krtap 15 & keratin associated protein 15 & -- & 4.7 \\
\hline 1421375_a_at & NM_01 I3I3 & S100ab & S100 calcium binding protein A6 (calcyclin) & cell proliferation & 4.5 \\
\hline 1419517_at & NM_028408 & $2900075 G 08 R i k$ & RIKEN cDNA 2900075 G08 gene & intracellular signaling cascade & 4.4 \\
\hline 1454736_at & $\mathrm{BMI} 19297$ & $49215 / 5 A 04 R i k$ & RIKEN cDNA 4921515A04 gene & regulation of transcription & 4.3 \\
\hline |436244_a_at & AU06768I & Tle2 & transducin-like enhancer of split 2, homolog of Drosophila E(spl) & $\begin{array}{l}\text { regulation of transcription/signal } \\
\text { transduction }\end{array}$ & 4.2 \\
\hline 1420594_at & NM_007525 & Bardl & BRCAI associated RING domain I & $\begin{array}{l}\text { DNA repair/regulation of transcription/ } \\
\text { apoptosis }\end{array}$ & 4.2 \\
\hline 1426093_at & AF220I4I & Trim34 & tripartite motif protein 34 & -- & 4.2 \\
\hline 1424748_at & $\mathrm{BC} 021504$ & Galntll & $\begin{array}{l}\text { UDP-N-acetyl-alpha-D-galactosamine:polypeptide N- } \\
\text { acetylgalactosaminyltransferase I I }\end{array}$ & metabolism & 4.1 \\
\hline 1416855_at & BB550400 & Gas I & growth arrest specific I & cell cycle arrest///programmed cell death & 4.0 \\
\hline 1422310_at & NM_009223 & Snn & stannin & - & 4.0 \\
\hline 1452463_x_at & BG966217 & $\operatorname{lgk}-\mathrm{V} 8$ & immunoglobulin kappa chain variable 8 (V8) & immune response & 4.0 \\
\hline |4504|5_at & NM_008805 & Pde6a & phosphodiesterase 6A, cGMP-specific, rod, alpha & signal transduction & 3.9 \\
\hline |4|8792_at & AF32656I & Sh3gl2 & SH3-domain GRB2-like 2 & --- & 3.9 \\
\hline 145|759_at & $\mathrm{BC} 013893$ & Masp2 & mannan-binding lectin serine protease 2 & cell adhesion/complement activation & 3.9 \\
\hline |41892|_at & AY059393 & Necll-pending & nectin-lke I & cell adhesion & 3.9 \\
\hline
\end{tabular}


$\infty$ Table 2: Selection of genes differentially expressed in AMLI-MTG I6-positive cells versus AMLI-MTGI6-negative cells grown in the presence of G-CSF for I6 $\mathrm{h}$. (Continued)

\begin{tabular}{|c|c|c|c|c|c|}
\hline 1416188_at & $\mathrm{BC} 00465 \mathrm{I}$ & Gm2a & GM2 ganglioside activator protein & sphingolipid metabolism & 3.8 \\
\hline 1448392_at & NM_009242 & Sparc & secreted acidic cysteine rich glycoprotein & cell proliferation & 3.8 \\
\hline 1419485_at & BB7̄59833 & Foxcl & forkhead box $\mathrm{Cl}$ & regulation of transcription & 3.7 \\
\hline 1419602_at & NM_01045I & Hoxa2 & homeo box $\mathrm{A} 2$ & regulation of transcription & 3.7 \\
\hline 1427358_a_at & BC02667I & Dapk I & death associated protein kinase I & apoptosis & 3.6 \\
\hline 1450827_at & NM_024245 & Kif23 & kinesin family member 23 & mitosis & 3.6 \\
\hline |421280_at & Z36357 & Gabral & gamma-aminobutyric acid (GABA-A) receptor, subunit alpha I & synaptic transmission & 3.5 \\
\hline 1452279_at & BB800282 & Pfc & properdin factor, complement & complement activation & 3.5 \\
\hline |4|5854_at & BB8I5530 & Kitl & kit ligand & cell proliferation/cell adhesion & 3.4 \\
\hline 1417513_at & $\mathrm{A} 1255184$ & Evi5 & ecotropic viral integration site 5 & --- & 3.3 \\
\hline |431379_a_at & AK005I53 & $S|c| 3 a l$ & solute carrier family I3 (sodium/sulphate symporters), member I & ion transport & 3.2 \\
\hline 1418476_at & NM_018827 & CrlfI & cytokine receptor-like factor I & --- & 3.2 \\
\hline 1416009_at & NM_019793 & Tm4sf8-pending & transmembrane 4 superfamily member 8 & signal transduction/cell proliferation & 3.1 \\
\hline |45 I633_a_at & BC025929 & GngI & $\begin{array}{c}\text { guanine nucleotide binding protein (G protein), gamma I } \\
\text { subunit }\end{array}$ & G-protein signaling pathway & -3.0 \\
\hline |425978_at & AF384055 & Srfcp-pending & SRF co-factor protein (cardiac and smooth muscle) & $\begin{array}{l}\text { regulation of transcription/positive } \\
\text { regulation of cell proliferation }\end{array}$ & -3.0 \\
\hline |425|53_at & BC008538 & Myh2 & myosin, heavy polypeptide 2 , skeletal muscle, adult & cytoskeleton organization & -3.1 \\
\hline | 448755_at & AFOII450 & Coll5al & procollagen, type $X V$ & cell adhesion & -3.2 \\
\hline 1433888_at & AV343478 & Atp2b2 & ATPase, Ca++ transporting, plasma membrane 2 & metabolism & -3.5 \\
\hline 1426868_x_at & AK003174 & Lmna & lamin A & cell morphology & -3.5 \\
\hline 1423292_a_at & BG072867 & Prx & periaxin & intracellular signaling cascade & -3.6 \\
\hline |44989|_a_at & NM_028523 & Esdn-pending & $\begin{array}{l}\text { endothelial and smooth muscle cell-derived neuropilin-like } \\
\text { molecule }\end{array}$ & (-) & -3.6 \\
\hline 1425708_at & AF285585 & RnfI7 & ring finger protein 17 & --- & -4.2 \\
\hline 1449836_x_at & NM_007546 & Biklk & Bcl2-interacting killer-like & apoptosis & -4.6 \\
\hline 14487|0_at & D87747 & Cxcr4 & chemokine (C-X-C motif) receptor 4 & defense response/hematopoiesis & -4.8 \\
\hline 1419227_at & NM_009839 & Cct6b & chaperonin subunit 6b (zeta) & protein folding & -5.0 \\
\hline 1455853_x_at & BB768303 & $\begin{array}{l}\text { 2700085A I4Rik } \\
\quad \text { (Sas) }\end{array}$ & $\begin{array}{c}\text { RIKEN cDNA 2700085A I } 4 \text { gene (Sarcoma amplified } \\
\text { sequence) }\end{array}$ & cell proliferation/signal transduction & -5.3 \\
\hline |416822_at & BC0I37II & Es2el & expressed sequence 2 embryonic lethal & --. & -5.4 \\
\hline 1422473_at & BM246564 & Pde4b & phosphodiesterase 4B, cAMP specific & signal transduction & -7.8 \\
\hline 1418499_a_at & NM_020574 & Kcne3 & $\begin{array}{c}\text { potassium voltage-gated channel, Isk-related subfamily, } \\
\text { gene } 3\end{array}$ & ion transport & -8.3 \\
\hline 1419537_at & NM_03 I I 98 & Tcfec & transcription factor EC & regulation of transcription & -20.6 \\
\hline 1449347_a_at & NM_021365 & XIr4 & X-linked lymphocyte-regulated 4 & chromatin remodeling? & -34.4 \\
\hline
\end{tabular}

$\stackrel{\infty}{\infty}$ Limits: $\mathrm{p}$-value $<0.01$; absolute fold change $>3$.

$\ddot{\infty}$ In bold are the AMLI-MTGI6-downregulated genes searched for AMLI-consensus motifs. 
focused on five of these genes, Fcer1a, Tcfec, Ptprcap, F2rl3, and Mgmt (Figure 2B, right), because they were among the most significantly downregulated genes. Fcer1a, Tcfec, Ptprcap, F2rl3, and Mgmt encode for known proteins. Specifically, Fcer1a is the Fc fragment of IgE and is involved in the immune response [22]; Tcfec is a transcription factor that induces, among other genes, the G-CSF receptor gene $[23,24]$; Ptprcap is a transmembrane protein associated with CD45, a key regulator of lymphocytes activation [25]; F2rl3 is a member of G protein-coupled proteaseactivated receptors (PARs) of the coagulation factor II (thrombin) and plays an important role in platelet activation [26]; Mgmt is a DNA repair enzyme that is frequently lost in cancer due to epigenetic silencing [27]. Downregulation of these genes was confirmed by real time RT-PCR (Figure 2C).

\section{Fcerla, Tcfec, Ptprcap, F2rl3, and Mgmt are direct} AMLI-MTGI6 targets

Quantitative chromatin immunoprecipitation (ChIP) with an anti-AML1 specific antibody, but not with an antiMTG16 antibody (data not shown), showed significant (p $<0.05$ ) enrichment of the region encompassing the AML1-consensus motif (see bars in figure 3A, left) relative to an arbitrary control region without the AML1-consensus motif in the mock clone chromatin for all five genes, indicating endogenous AML1 binding at these regions (Figure 3B). ChIP with an anti-MTG16 antibody showed instead a significant enrichment of exogenous AML1MTG16 in the same chromatin regions in the A16 clones (Figure 3B). The human homologues of these genes also contain an AML1-consensus sequence(s) in the $10 \mathrm{~Kb}$ region surrounding the transcription start site, pointing to

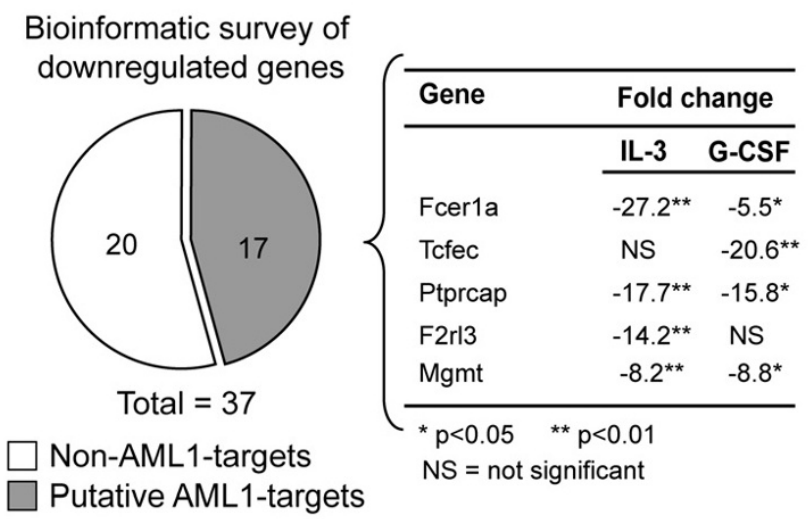

Non-AML1-targets

C

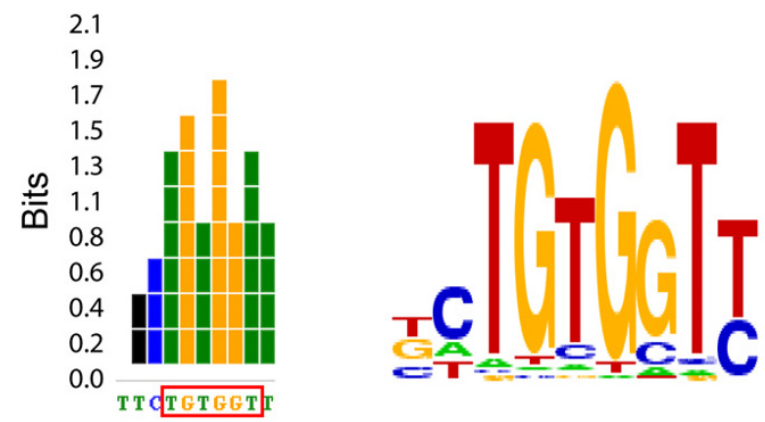

Multilevel consensus sequence

Real time RT-PCR
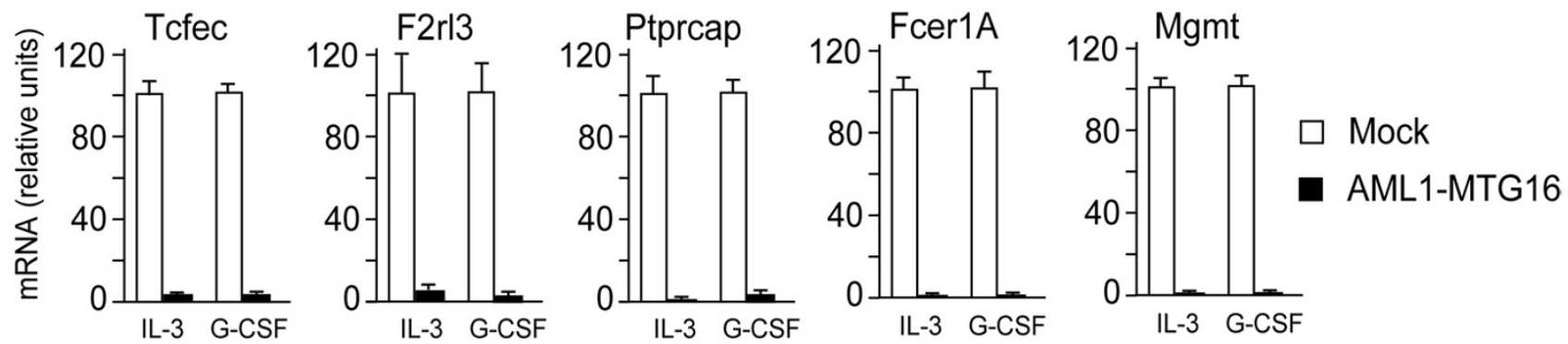

Figure 2

AMLI-MTG I6-induced downregulation of putative AMLI-targets. A. The AMLI-consensus motif, containing the AMLI-consensus sequence (framed), found by bioinformatic analysis of the genes significantly downregulated in AI 6 cells. The height of the columns associated with each nucleotide is proportional to the conservation level. The "logo" representation of the motif instead indicates in which proportion the single bases are present at each position. B. Seventeen out of the 37 downregulated genes are putative AML I-targets. The fold-changes of five of the most significantly downregulated genes are reported at right. C. Real time RT-PCR confirmed the significant $(p<0.01)$ downregulation of the five genes. 
able 3: Selection of putative AMLI-target genes downregulated in AMLI-MTG I6-positive cells versus AMLI-MTG I6-negative cells.

\begin{tabular}{|c|c|c|c|c|c|c|}
\hline Affymetrix ID & NCBI acc. number & Gene Symbol & Gene Title & GO/Ingenuity annotations & Fold change IL-3 & Fold change G-CSF \\
\hline 1417338_at & U03487 & Epb4.2 & erythrocyte protein band 4.2 & structural function & -3.3 & --- \\
\hline |433888_at & AV343478 & Atp2b2 & ATPase, $\mathrm{Ca}++$ transporting, plasma membrane 2 & metabolism & --- & -3.5 \\
\hline 1426868_x_at & AK003I74 & Lmna & $\operatorname{lamin} A$ & cell morphology & --- & -3.5 \\
\hline 1423292_a_at & BG072867 & $\operatorname{Prx}$ & periaxin & intracellular signaling cascade & --- & -3.6 \\
\hline |44989|_a_at & NM_028523 & Esdn-pending & $\begin{array}{l}\text { endothelial and smooth muscle cell-derived } \\
\text { neuropilin-like molecule }\end{array}$ & --- & --- & -3.6 \\
\hline | 425708_at & AF285585 & Rnfl7 & ring finger protein 17 & --- & --- & -4.2 \\
\hline 1419124_at & NM_133829 & AW212394 & expressed sequence AW212394 & --- & -4.4 & --- \\
\hline |425597_a_at & AW060288 & Qk & quaking & apoptosis & -4.6 & --- \\
\hline 1419227_at & NM_009839 & Cct6b & chaperonin subunit 6b (zeta) & protein folding & --- & -5.0 \\
\hline 1455853_x_at & BB768303 & 2700085A A 4Rik (Sas) & $\begin{array}{l}\text { RIKEN cDNA 2700085A I4 gene (Sarcoma } \\
\text { amplified sequence) }\end{array}$ & cell proliferation/signal transduction & --- & -5.3 \\
\hline | 422473_at & BM246564 & Pde4b & phosphodiesterase 4B, cAMP specific & signal transduction & --- & -7.8 \\
\hline |421309_at & NM_008598 & Mgmt & O-6-methylguanine-DNA methyltransferase & DNA repair & -8.2 & --- \\
\hline 1421288_at & NM_007975 & $\mathrm{F} 2 \mathrm{r} / 3$ & coagulation factor II (thrombin) receptor-like 3 & $\begin{array}{c}\text { blood coagulation/G-protein signaling } \\
\text { pathway }\end{array}$ & -14.2 & --- \\
\hline 1449347_a_at & NM_021365 & XIr4 & X-linked lymphocyte-regulated 4 & chromatin remodelling? & -16.9 & -34.4 \\
\hline |4485| |_at & NM_016933 & Ptprcap (I) & $\begin{array}{l}\text { protein tyrosine phosphatase, receptor type, C } \\
\text { polypeptide-associated protein }\end{array}$ & phosphatase signaling pathway & -17.7 & --- \\
\hline 1419537_at & NM_03II98 & Tcfec & transcription factor EC & regulation of transcription & --- & -20.6 \\
\hline |42|775_at & NM_010184 & Fcerla & Fc receptor, IgE, high affinity I, alpha polypeptide & signal transduction & -27.2 & --- \\
\hline
\end{tabular}

Motif conservation significance: $\mathrm{p}<10 \mathrm{E}-5$.

(I) The Ptprcap AMLI-consensus motif is located in an intron of a 5 ' adjacent gene (Corolb). 
A In silico analysis

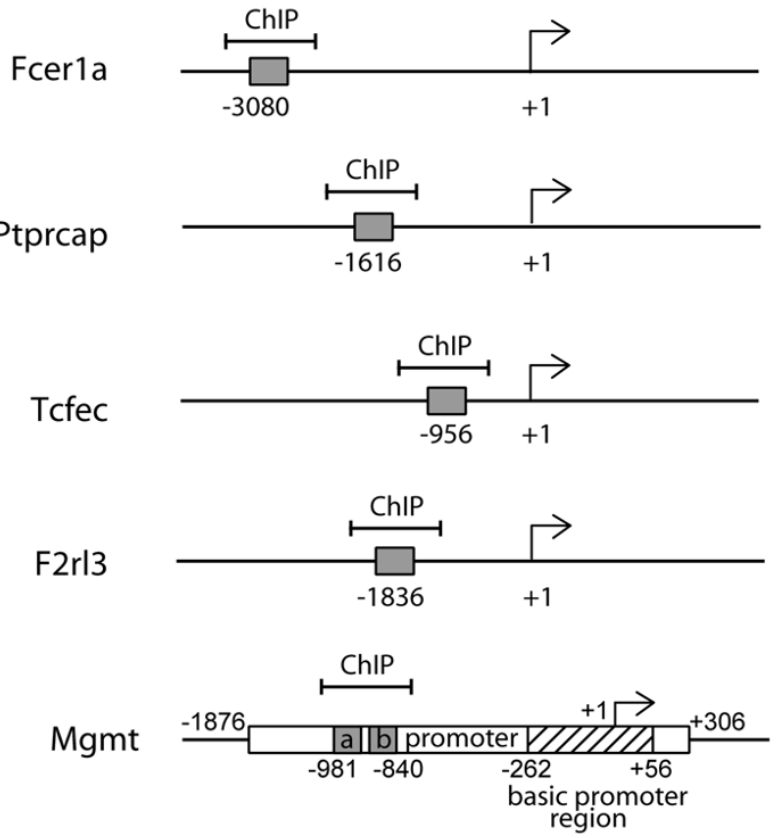

AML1-consensus motif

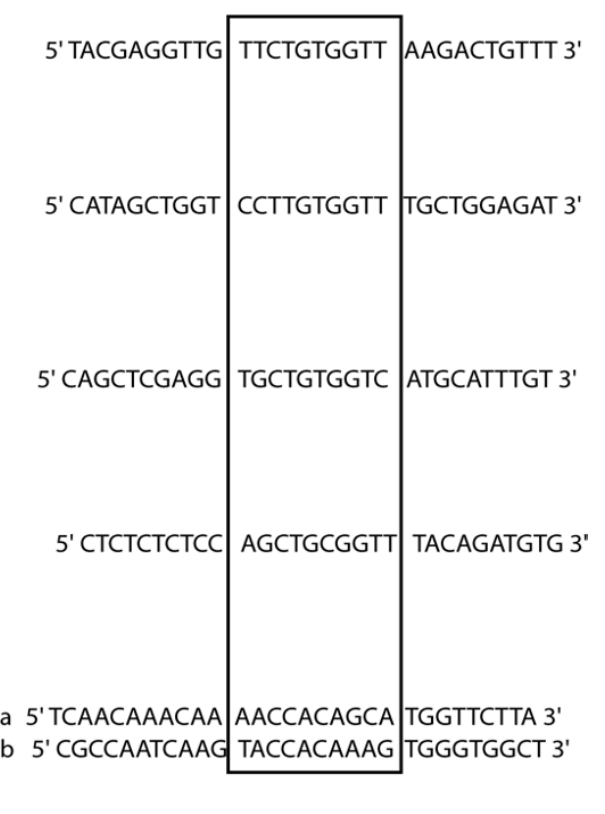

B ChIP
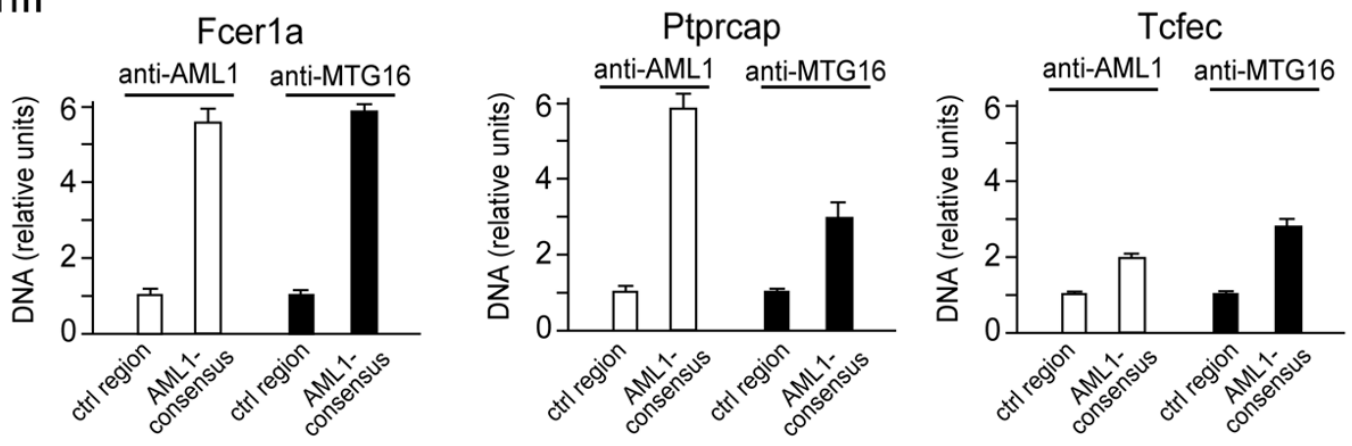

F2rl3
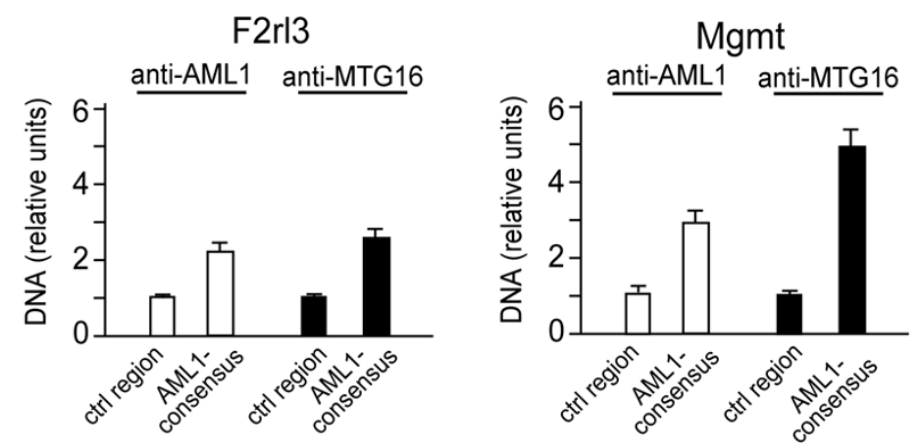

mock

AML1-MTG16

Figure 3

AMLI-target gene validation. A. Relative position of the AMLI-consensus motifs (left) and their sequence (right) in the five putative AML I-target genes that were analyzed by ChIP. B. Quantitative ChIP analysis with antibodies either against AMLI or MTG 16 showing a significant $(p<0.05)$ enrichment of chromatin containing AMLI-consensus motifs vs. chromatin containing a control region in AMLI-MTG I6-negative and AMLI-MTGI6-positive cells, respectively. 
these five genes as novel, bona fide direct AML1-targets genes.

\section{Repressive chromatin changes at AMLI-MTG I6- downregulated targets}

We previously demonstrated that AML1-MTG16 interacts with both HDAC1 and HDAC3 [28]. Further, we found that AML1-MTG16 can induce downregulation marked by repressive histone hypoacetylation at the Csf1r chromatin [19]. Here we show that, in A16 cells, the chromatin associated with both the region containing the AML1-consensus motif and the region encompassing the transcription start site of Fcer1a, Tcfec, Ptprcap, F2rl3, and Mgmt (Figure $3 \mathrm{~A})$ displays a significant $(\mathrm{p}<0.05)$ decrease of acetylated histone H4 (Ac-H4), and a significant ( $\mathrm{p}<0.05)$ increase of H3K9 tri-methylation (Tri-Met-H3-K9) (Figure 4A), supporting the acquisition of a repressive chromatin state [29-31].

Repressive histone modifications are often associated with aberrant hypermethylation at $\mathrm{CpG}$ islands present in the 5 ' regulatory regions of many genes $[32,33]$ and references within). By using the CpG island searcher [34], a software for the identifying CpG islands, we could identify a CpG island only in the Mgmt promoter region [35] (Figure 4B). Bisulfite sequencing analysis of this region detected hypermethylation in AML1-MTG16-positive cells (Figure 4B).

The overall epigenetic analysis indicates that downregulation of AML1-targets by AML1-MTG16 can be achieved, even in the absence of DNA methylation, when there is a critical quantitative level of repressive histone changes.

\section{Discussion}

In this study we show the effectiveness of integrating global gene expression array analysis with a bioinformatic approach aimed at detecting AML1-consensus sequences for identifying novel putative direct AML1-targets downregulated by AML1-MTG16 in 32D cells. Downregulation of these genes is marked by a distinct repressive chromatin profile.

When we surveyed the 37 most significantly downregulated genes for the presence of the AML1-consensus motif(s) in the $10 \mathrm{~Kb}$ region encompassing the transcription start site, we closed on seventeen putative direct AML1-MTG16 targets. For five of these genes, Fcer1a, Tcfec, Ptprcap, F2rl3 and Mgmt, which were among the most significantly downregulated, we were able to demonstrate, using ChIP analysis, the binding of both AML1 and AML1-MTG16 to the gene regions containing the AML1-motifs. Thus, our two-tier approach, combining gene expression array analysis with bioinformatic survey for transcription factor-consensus sequences, seems to be a powerful strategy for identifying transcription factor targets, which would otherwise be missed when using conventional gene expression array analysis alone.

The chromatin of the five downregulated genes, Fcer1a, Tcfec, Ptprcap, F2rl3, and Mgmt, was marked not only by significant levels of histone $\mathrm{H} 4$ hypoacetylation, but also by significant levels of repressive histone H3-K9 trimethylation, suggesting that AML1-MTG16 might induce the recruitment of both histone deacetylases [28] and histone methyltransferases. Apparently, a critical quantity of repressive histone modifications, even in the absence of CpG methylation, might per se be sufficient to "lock in" a transcriptionally downregulated state. In the case of Mgmt, which has a CpG island, it is instead possible that the accumulation of histone repressive changes preceded CpG hypermethylation [[36], and references within].

It is noteworthy that all the genes for which we demonstrated AML1-MTG16-induced epigenetic downregulation encode for functions relevant to either hematopoiesis and/or leukemogenesis. We would like to underline that downregulation of two of the genes that we identified might be relevant to AML1-MTG16-induced leukemogenesis. One of these genes is Tcfec, whose human counterpart encodes a transcription factor that induces the granulocyte colony stimulating factor receptor G-CSFR $[23,24]$. Remarkably, Tcfec downregulation in A16 cells is paralleled by a significant downregulation of G-csfr (data not shown), indicating that AML1-MTG16 might have triggered a coordinated cascade of transcriptional downregulation, as we observed in other differentiation model systems $[37,38]$. The second gene is $M g m t$, encoding the DNA repair enzyme O6-Methylguanine-DNA-methyltransferase, which is frequently silenced and hypermethylated in leukemia [39]. MGMT epigenetic silencing is thought to lead to random mutations in cancer [40]. A recent study has shown that expression of different acute myeloid leukemia fusion proteins, including AML1MTG8, leads to downregulation of several DNA repair genes [41]. Thus, the induction of a "mutator phenotype" might be a common consequence of leukemia fusion protein expression.

A few global gene expression studies on cells expressing exogenous AML1-MTG8 have been recently described [42-44]. Given the use of different cell systems, it is difficult to compare the differentially expressed genes in AML1-MTG16-positive 32D cells with the differentially expressed genes reported for AML1-MTG8. Nevertheless, we could identify a few gene families (e.g. S100 Calciumbinding proteins) that are similarly affected by both AML1-MTG8 and AML1-MTG16 even in different cell contexts. Extending our study to the comparison of the epigenetic signatures imposed by either exogenous AML1- 
A ChIP anti-tri-Met-H3-K9

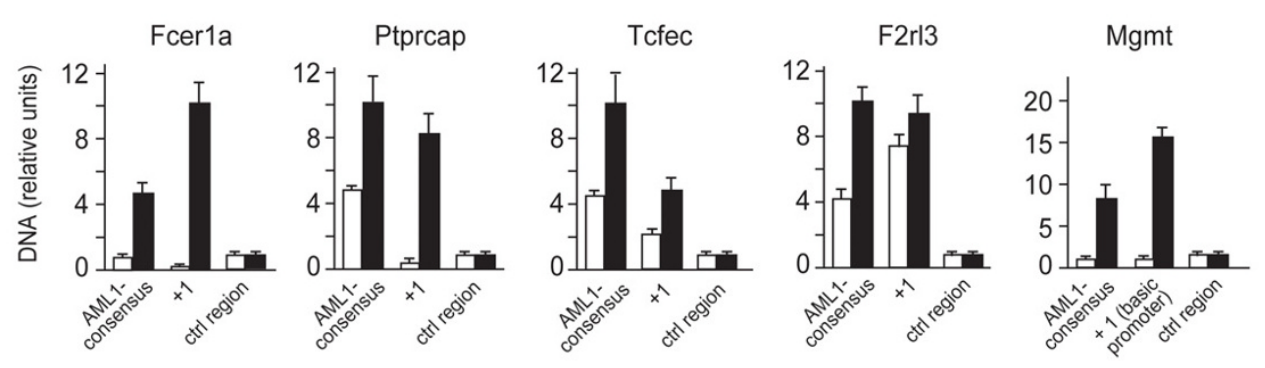

ChIP anti-Acetylated $\mathrm{H} 4$

Fcer1a Ptprcap

Tcfec

$\mathrm{F} 2 \mathrm{rl3}$

Mgmt
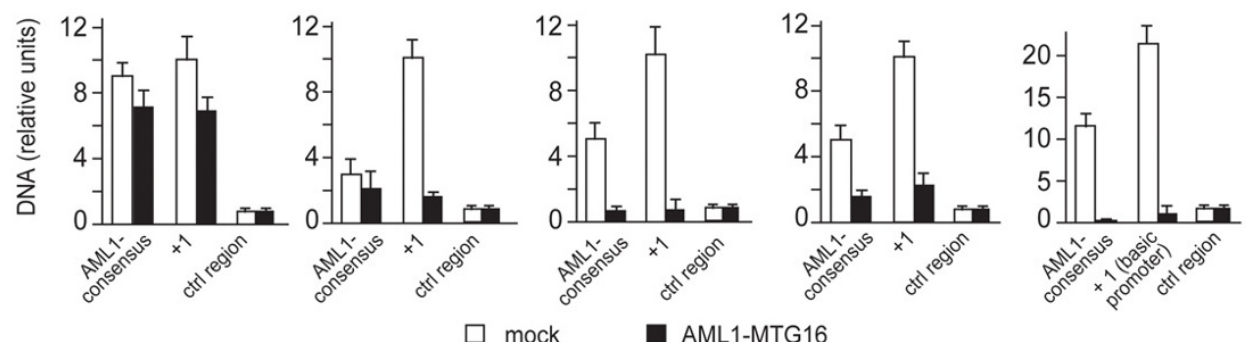

B

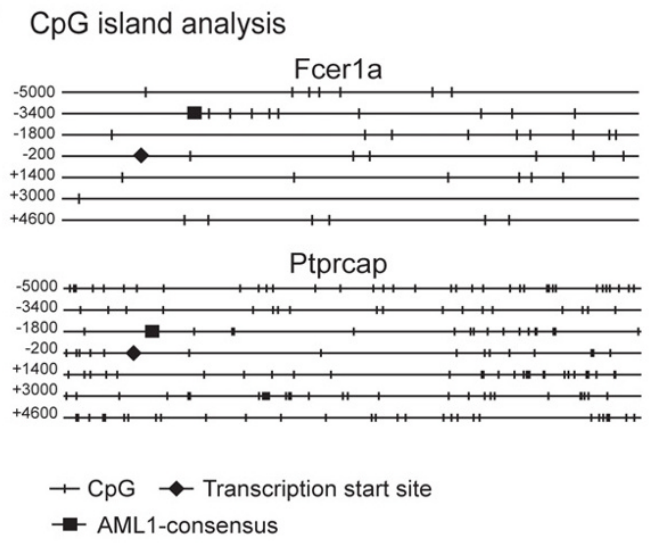

$\mathrm{CpG}$ island Searcher limits:

$\% \mathrm{GC}=60, \mathrm{ObsCpg} / \mathrm{ExpCpG}=0.65$,

lenght $=300$, distance $=100$

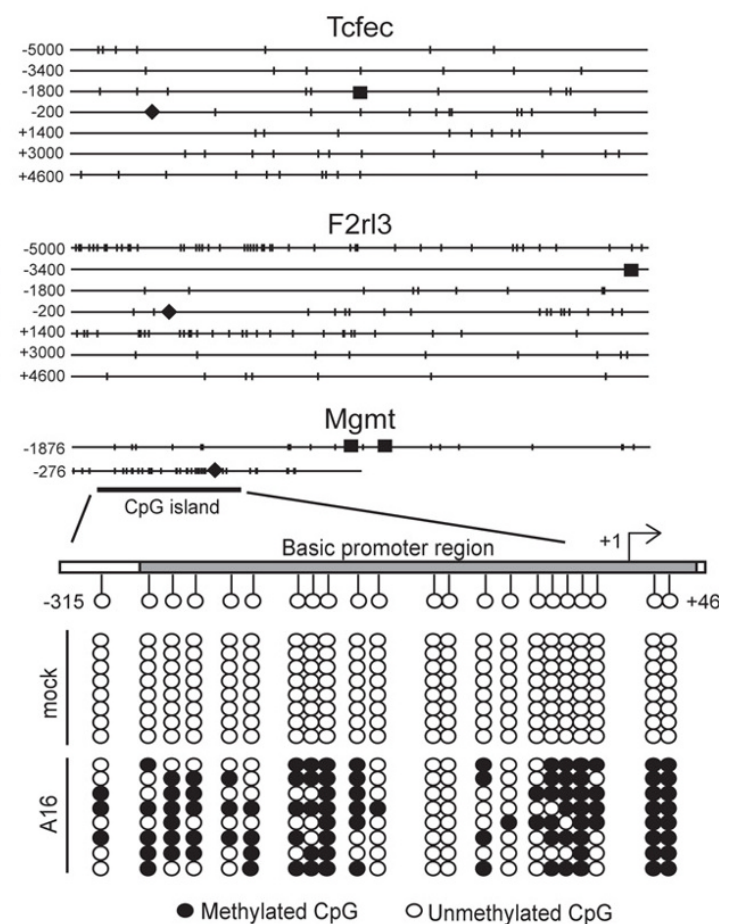

\section{Figure 4}

Repressive epigenetic changes at the AMLI-targets. A. ChIP with antibodies against either acetylated histone H4 or trimethylated histone $\mathrm{H} 3$ Lysine 9 (tri-Met-H3-K9) followed by quantitative PCR with primers amplifying a region encompassing either the transcription start site $(+I)$ or the AMLI-consensus detected a different level of repressive histone changes in all five genes in A 16 cells. B. In silico analysis identified a CpG island only in the Mgmt promoter. This CpG island is hypermethylated in Al 6 cells (bottom, right). 
MTG16 or exogenous AML1-MTG8 in the very same cell context (e.g. 32D cells) might enable us to narrow down additional critical epigenetic signatures consequent to $\mathrm{t}(8 ; 21)$ and $\mathrm{t}(16 ; 21)$ translocations.

\section{Conclusion}

In this study, we show that AML1-MTG16, the leukemia fusion protein associated with the non-random chromosome translocation $\mathrm{t}(16 ; 21)(\mathrm{q} 24 ; \mathrm{q} 22)$, can impose transcriptional downregulation marked by a distinct epigenetic signature at specific AML1-target sites in the genome. Thus, our findings further support the hypothesis that non-random genetic abnormalities can lead to non-random epigenetic changes in leukemia cells $[19,45]$.

\section{Methods \\ Cell cultures}

Stable clones obtained from mouse myeloid 32D cells infected either with pLNCX2-AML1-MTG16 (A16 clones) or the empty vector pLNCX2 (mock clones) were previously described [19]. Two prototypic A16 clones and two prototypic mock clones were used in this study. Cells were maintained in the presence of $10 \mathrm{ng} / \mathrm{ml}$ of murine IL-3 (BD Biosciences, San Jose, CA, USA) in RPMI 1640 medium supplemented with $10 \%$ fetal calf serum, $1 \%$ antibiotics (penicillin/streptomycin), adjusting the cell density to $2 \times 10^{5}$ cells/ml daily. To induce granulocyte differentiation, cells were washed in RPMI medium, and IL-3 was replaced with $10 \mathrm{ng} / \mathrm{ml}$ human G-CSF (Amgen, Thousand Oaks, CA, USA). Differentiation was microscopically evaluated on cytospin preparations stained with May-Grünwald-Giemsa.

\section{RNA extraction and microarray hybridization}

Total RNA was extracted with RNeasy mini kit (Qiagen, Hilden, Germany) and treated with DNase (Qiagen). Double stranded cDNA was generated from $5 \mu \mathrm{g}$ RNA using Superscript ds cDNA synthesis kit (Invitrogen, Carlsbad, CA, USA) and T7-oligo(dT) primers. The cDNA was purified with GeneChip Sample Cleanup Module (Affymetrix, Santa Clara, CA, USA) and used to synthesize biotin-labeled cRNA with Enzo RNA transcript Labeling Kit (Enzo Life Science, Farmingdale, NY, USA). Purified cRNA was quantified by spectrophotometric methods and the concentration was adjusted in order to exclude the carryover of unlabeled RNA. $11 \mu \mathrm{g}$ of cRNA were then fragmented in fragmentation buffer (Affymetrix) at $95^{\circ} \mathrm{C}$ for 35 minutes and hybridized for $16 \mathrm{~h}$ at $45^{\circ} \mathrm{C}$ onto MOE430A microarrays (Affymetrix). After washing and staining, the chips were scanned in a Hewett-Packard/ Affymetrix scanner at $570 \mathrm{~nm}$. For all the samples the $5^{\prime} /$ 3 ' ratios of Gapdh were 0.7 - 0.9. In comparative experiments the scaling factor, noise and presence calls were similar. Gene expression data represent the average of two independent experiments.

\section{Microarray data analysis}

The arrays were normalized by geometric mean intensity for each probe set and scaled using log2 transformation for further analysis. Comparison between the A16 and mock clones grown with either IL-3 or G-CSF was done using Spotfire Decision Site. This comparison generated a p-value from a t-test to statistically extract significant changes in mRNA expression levels between the groups. p-values $<0.05$ were considered significant. The null hypothesis is that the samples between the groups are derived from the same population i.e. there is no significant differential expression. The t-test looks at the variance within the groups as well as between them. To be considered significantly differentially expressed the variance had to be greater between than within the groups to a level of $\mathrm{p}<0.05$. Ratios were generated by dividing the average of the unlogged control data by the average of the unlogged AML1-MTG16 data. Ratios were then portrayed as positive or negative fold change between A16 and mock. To confirm statistical significance of these ratios the differentially expressed genes had to satisfy an arbitrary cut-off ratio as well as having a p-value $<0.05$ (see Results section). Analysis of the protein networks was performed by using Ingenuity Pathways Analysis (Ingenuity Systems, Redwood City, CA), software able to identify molecular networks based on known functional or physical interactions among the proteins encoded by the differentially expressed genes.

\section{Search of AMLI-consensus sequence in differentially expressed genes}

The well-annotated genes differentially expressed in the A16 clone versus the mock clone either in the presence of IL-3 or G-CSF ( $p<0.01$ and absolute fold change $>3$ ) were searched for the AML1-consensus sequence "5'-TG(T/ C)GGT-3"' in the $10 \mathrm{~kb}$ region surrounding the transcription initiation sites (from $-5000 \mathrm{bp}$ to $+5000 \mathrm{bp}$ ) using an in-house built PERL script. A 400 bp sequence flanking the potential AML1-binding sites (200 bp on each side) was extracted and analyzed with MEME, which is a software package to discover motifs in groups of related DNA sequences [46], and with multiple sequence alignment to test whether additional conserved motifs in the surrounding regions could be identified and to assess the sequence conservation extending the potential AML1-binding sites.

\section{Real-time RT-PCR}

Total RNA was obtained using Trizol (Invitrogen), treated with DNase I (Ambion, Austin, TX, USA), retrotranscribed with SuperScript ${ }^{\mathrm{TM}}$ First-Strand Synthesis System (Invitrogen) and amplified by Real-time RT-PCR on an iCycler (Bio-Rad, Hercules, CA, USA) by using iQ SYBR Green Supermix (Bio-Rad) and primers specific for $\gamma$ actin, F2rl3, Fcer1a, Ptprcap, Tcfec, and Mgmt (Table 4). Transcript levels of the genes of interest were quantitated by the Delta- 
Table 4: Primers used for real time RT-PCR, quantitative ChIP, and bisulfite sequencing.

\begin{tabular}{|c|c|c|}
\hline Primer name & Orientation & Sequence \\
\hline \multicolumn{3}{|l|}{ Real time $P C R$ primers } \\
\hline \multirow[t]{2}{*}{$\gamma$-Actin } & sense & 5'-GCCGGCTTACACTGCGCTTCTT-3' \\
\hline & antisense & 5'-TTCTGGCCCATGCCCACCAT-3' \\
\hline \multirow[t]{2}{*}{$\mathrm{F} 2 \mathrm{rl3}$} & sense & 5'-GCTTCTGATCCTGGCAGCATG-3' \\
\hline & antisense & 5'-GTGTCACTGTCGTTGGCACAG-3' \\
\hline \multirow[t]{2}{*}{ Fcerla } & sense & 5'-CCCTTTCCTGCTATGGGAACA-3' \\
\hline & antisense & 5'-GCAGCCAATCTTGCGTTACATT-3' \\
\hline \multirow[t]{2}{*}{ Ptprcap } & sense & 5'-GGATGAAGAGGATGCAGAAGAT-3' \\
\hline & antisense & 5'-CTGACTCCTATAGTGCAGTGAC-3' \\
\hline \multirow[t]{2}{*}{ Tcfec } & sense & 5'-AGTCTAATGATCCTGATATGCGC-3' \\
\hline & antisense & 5'-TCCTGAATCCGGAGCCTAAGC-3' \\
\hline \multirow[t]{2}{*}{ Mgmt } & sense & 5'-GAACTTGGCAGAATGGCTGAG-3' \\
\hline & antisense & 5'-GGTGATGGAGAGCAGGCAA-3' \\
\hline \multicolumn{3}{|l|}{ ChIP primers } \\
\hline \multirow[t]{2}{*}{ Ptprcap- AMLI-consensus } & sense & 5'-GTCCTGCAGCTGGTGTTTACAG-3' \\
\hline & antisense & 5'-CTGGTCTCTGAGTGGCTGCA-3' \\
\hline \multirow[t]{2}{*}{ Ptprcap-transcription start } & sense & 5'-GAGGTCTGACAAGTTAGCTGTA-3' \\
\hline & antisense & 5'-ACCCTGTAACTCACTTCTCACT-3' \\
\hline \multirow[t]{2}{*}{ Tcfec- AMLI-consensus } & sense & 5'AGAGCTTGACTAGAATGGATTT-3' \\
\hline & antisense & 5'-GGTGCAACCCATTCATGGCTT-3' \\
\hline \multirow[t]{2}{*}{ Tcfec-transcription start } & sense & 5'-AGTCACACCACTGGAGTAGTTTT-3' \\
\hline & antisense & 5'-CССTCGTCTCATAACCTAAGCA-3' \\
\hline \multirow{2}{*}{ Fcerla- AMLI-consensus } & sense & 5'-GGCCACTGACTTCAGTGTGAA-3' \\
\hline & antisense & 5'-TGCATTCCAGTTCTCTGCAAGA-3' \\
\hline \multirow{2}{*}{ Fcer la-transcription start } & sense & 5'-AGGTGTCAGCTGAAGGTACAATA-3' \\
\hline & antisense & 5'-СССАССАТGАСАСТСТСТААAT-3' \\
\hline \multirow[t]{2}{*}{ F2rl3-AMLI-consensus } & sense & 5'-AGGGTGTCTCTCTGAATCTGGA-3' \\
\hline & antisense & 5'-GGCAAGTCTGTTATCTCAGCAT-3' \\
\hline \multirow[t]{2}{*}{ F2rl3-transcription start } & sense & 5'-TTGGAGGAAGGCTGGATTGTTAT-3' \\
\hline & antisense & 5'-CCCATTGGGATCTGCTTGCTCA-3' \\
\hline \multirow[t]{2}{*}{ Mgmt-AMLI-consensus } & sense & 5'-GAGCTGCACACTGGGAAGATG-3' \\
\hline & antisense & 5'-GTGTACCAGATGCTGTGCAGG-3' \\
\hline \multirow[t]{2}{*}{ Mgmt-basic promoter } & sense & 5'-CAGTTTCAGGTCTGGAAGAAGAG-3' \\
\hline & antisense & 5'-AGCTGTGGGCTTGTAGTCCGAG-3' \\
\hline \multirow[t]{2}{*}{ Control region } & sense & 5'-ATGCAACACACAACAAAGCAAA-3' \\
\hline & antisense & 5'-GGCCAAATGAGGTTGTGTCCT-3' \\
\hline \multicolumn{3}{|c|}{ Bisulfite sequencing primers } \\
\hline \multirow[t]{2}{*}{ Mgmt-CpG-| st PCR } & sense & 5'-TAGTGATTGGATTTTTAGTGGGT-3' \\
\hline & antisense & 5'-СТАТСТСССТАААСТТСААСТС-3' \\
\hline \multirow{2}{*}{ Mgmt-CpG-2nd PCR } & sense & 5'-GTGAGAAGGTGTAGTTTAGTTT-3' \\
\hline & antisense & 5'-СТСACCAACTTACAAACTACAA-3' \\
\hline
\end{tabular}


delta Ct method, using the house keeping gene $\gamma$-actin for normalization. The amplification efficiency, evaluated from the sample slopes, was similar for all the samples analyzed in the same experiment. Two independent experiments were performed in triplicate using two mock clones and two A16 clones. Significance was determined by using the Student t-test.

\section{Quantitative chromatin immunoprecipitation (ChIP)}

ChIP was performed using reagents purchased from Upstate (Charlottesville, VA, USA) following the manufacturer's protocol. AML1 and AML1-MTG16 binding was assessed by ChIP with antibodies against either the AML1 C-terminus (Santa Cruz Biotechnology, Santa Cruz, CA, USA), or the MTG16 C-terminus [28], respectively. Histone hallmarks of repressive chromatin were assessed by ChIP with antibodies against acetyl-histone H4 (Upstate) and trimethyl-K9 at histone H3 (Upstate). Control ChIPs were performed without the respective antibodies. The immunoprecipitated DNA was amplified by real-time PCR with primers specific for regions encompassing the AML1-consensus, the transcription start site, or a control region (Table 4). The DNA relative enrichment was calculated by using the Delta-delta Ct method. The PCR signals obtained for each gene region were normalized to the PCR signal obtained from the input DNA (total chromatin fraction) and compared to a control region approximately $15 \mathrm{~kb}$ downstream of F2rl3 transcription start site. Two independent experiments were performed in triplicate, and significance was calculated by using the Student t-test.

\section{Bisulfite sequencing}

Genomic DNA was extracted with DNAzol (Invitrogen) according to the manufacturer's instructions. DNA was modified by sodium bisulfite treatment as previously described [47]. Mgmt CpG island was amplified by nested PCR by using the primers indicated in Table 4 . The PCR fragments were subcloned into pGEM-T (Promega, San Luis Obispo, CA, USA) and 20 clones for each PCR fragment were sequenced.

\section{Authors' contributions}

SR developed the 32D clones, designed and carried out the molecular genetics studies, participated in the microarray analysis, and prepared a draft of the manuscript. ATH contributed to the microarray analysis and critically reviewed the manuscript. PL performed the bioinformatic genome search of AML1-motifs. CS provided technical help for the real time RT-PCR and ChIP analyses. PV performed the microarray data analysis. NS conceived the hypothesis and critically reviewed the entire manuscript. All authors read and approved the final manuscript.

\section{Additional material}

\section{Additional File 1}

Evidence of functional AML1 haploinsufficiency in AML1-MTG16expressing cells. This figure shows the Ingenuity Pathways Analysis of the global gene expression changes identified in AML1-MTG16-expressing cells.

Click here for file

[http://www.biomedcentral.com/content/supplementary/14712164-8-38-S1.pdf]

\section{Acknowledgements}

We wish to thank Frank Staal, Justine Peeters, Violeta Stoyanova, Leontine van Unen (ErasmusMC, Rotterdam, The Netherlands), and Alan Hutson (Roswell Park Cancer Institute, Buffalo, NY) for technical support and critical discussions. This work was supported through Erasmus MC funds (ATH) and RPCl institutional funds (NS).

\section{References}

I. Rosmarin AG, Yang Z, Resendes KK: Transcriptional regulation in myelopoiesis: Hematopoietic fate choice, myeloid differentiation, and leukemogenesis. Exp Hematol 2005, 33:|3|-|43.

2. Evans T: Regulation of hematopoiesis by retinoid signaling. Exp Hematol 2005, 33: 1055-106I.

3. Kitabayashi I, Yokoyama A, Shimizu K, Ohki M: Interaction and functional cooperation of the leukemia-associated factors AMLI and p300 in myeloid cell differentiation. Embo J 1998 , I 7:2994-3004.

4. Michaud J, Scott HS, Escher R: AMLI interconnected pathways of leukemogenesis. Cancer Invest 2003, 2 I : I 05- 136.

5. Otto F, Lubbert M, Stock M: Upstream and downstream targets of RUNX proteins. J Cell Biochem 2003, 89:9-18.

6. Yamagata $T$, Maki $K$, Mitani $K$ : RunxI/AMLI in normal and abnormal hematopoiesis. Int J Hematol 2005, 82: I-8.

7. Meyers S, Downing JR, Hiebert SW: Identification of AML-I and the $(8 ; 2 I)$ translocation protein (AML- I/ETO) as sequencespecific DNA-binding proteins: the runt homology domain is required for DNA binding and protein-protein interactions. Mol Cell Biol 1993, I3:6336-6345.

8. Scandura JM, Boccuni P, Cammenga J, Nimer SD: Transcription factor fusions in acute leukemia: variations on a theme. Oncogene 2002, 2 I:3422-3444.

9. Song WJ, Sullivan MG, Legare RD, Hutchings S, Tan X, Kufrin D, Ratajczak J, Resende IC, Haworth C, Hock R, Loh M, Felix C, Roy DC, Busque L, Kurnit D, Willman C, Gewirtz AM, Speck NA, Bushweller JH, Li FP, Gardiner K, Poncz M, Maris JM, Gilliland DG: Haploinsufficiency of CBFA2 causes familial thrombocytopenia with propensity to develop acute myelogenous leukaemia. Nat Genet 1999, 23:166-175.

10. Miyoshi H, Shimizu K, Kozu T, Maseki N, Kaneko Y, Ohki M: t(8;2I) breakpoints on chromosome $2 \mathrm{I}$ in acute myeloid leukemia are clustered within a limited region of a single gene, AMLI. Proc Natl Acad Sci U S A 1991, 88: I043 I-10434.

II. Erickson P, Gao J, Chang KS, Look T, Whisenant E, Raimondi S, Lasher R, Trujillo J, Rowley J, Drabkin H: Identification of breakpoints in $t(8 ; 2 I)$ acute myelogenous leukemia and isolation of a fusion transcript, AMLI/ETO, with similarity to Drosophila segmentation gene, runt. Blood I992, 80: I825-I83I.

12. Nisson PE, Watkins PC, Sacchi N: Transcriptionally active chimeric gene derived from the fusion of the AMLI gene and a novel gene on chromosome 8 in $\mathbf{t}(8 ; 2 I)$ leukemic cells [published erratum appears in Cancer Genet Cytogenet 1993 Mar;66(I):8I]. Cancer Genet Cytogenet 1992, 63:8I-88.

13. Gamou T, Kitamura E, Hosoda F, Shimizu K, Shinohara K, Hayashi Y, Nagase T, Yokoyama Y, Ohki M: The partner gene of AMLI in $\mathbf{t}(16 ; 21)$ myeloid malignancies is a novel member of the MTG8(ETO) family. Blood 1998, 9 1:4028-4037. 
14. Hiebert SW, Lutterbach B, Amann J: Role of co-repressors in transcriptional repression mediated by the $t(8 ; 21), t(16 ; 2 I)$, $\mathbf{t}(\mathbf{1 2 ; 2} \mathbf{I})$, and inv(16) fusion proteins. Curr Opin Hematol 200I, 8: $197-200$.

15. Rossetti S, Hoogeveen AT, Sacchi N: The MTG proteins: chromatin repression players with a passion for networking. Genomics 2004, 84: I-9.

16. Minucci S, Maccarana M, Cioce M, De Luca P, Gelmetti V, Segalla S, Di Croce L, Giavara S, Matteucci C, Gobbi A, Bianchini A, Colombo E, Schiavoni I, Badaracco G, Hu X, Lazar MA, Landsberger N, Nervi C, Pelicci PG: Oligomerization of RAR and AMLI transcription factors as a novel mechanism of oncogenic activation. Mol Cell 2000, 5:8I I-820.

17. Zhang J, Hug BA, Huang EY, Chen CW, Gelmetti V, Maccarana M, Minucci S, Pelicci PG, Lazar MA: Oligomerization of ETO is obligatory for corepressor interaction. Mol Cell Biol 200I, 21:156-163.

18. Liu Y, Cheney MD, Gaudet J], Chruszcz M, Lukasik SM, Sugiyama D, Lary J, Cole J, Dauter Z, Minor W, Speck NA, Bushweller JH: The tetramer structure of the Nervy homology two domain, NHR2, is critical for AMLI/ETO's activity. Cancer Cell 2006, 9:249-260.

19. Rossetti S, Van Unen L, Touw IP, Hoogeveen AT, Sacchi N: Myeloid maturation block by AMLI-MTGI 6 is associated with CsfIr epigenetic downregulation. Oncogene 2005, 24:5325-5332.

20. Ahn MY, Huang G, Bae SC, Wee HJ, Kim WY, Ito Y: Negative regulation of granulocytic differentiation in the myeloid precursor cell line 32Dcl3 by ear-2, a mammalian homolog of Drosophila seven-up, and a chimeric leukemogenic gene, AMLI/ETO. Proc Natl Acad Sci U S A 1998, 95:1812-18I7.

21. Kohzaki H, Ito K, Huang G, Wee H, Murakami Y, Ito Y: Block of granulocytic differentiation of $32 \mathrm{Dcl} 3$ cells by AMLI/ ETO(MTG8) but not by highly expressed Bcl-2. Oncogene 1999, I 8:4055-4062.

22. Kinet JP: The high-affinity IgE receptor (Fc epsilon RI): from physiology to pathology. Annu Rev Immunol 1999, 17:93I-972.

23. Rehli M, Sulzbacher S, Pape S, Ravasi T, Wells CA, Heinz S, Sollner L El Chartouni C, Krause SW, Steingrimsson E, Hume DA, Andreesen $R$ : Transcription factor Tfec contributes to the IL-4-inducible expression of a small group of genes in mouse macrophages including the granulocyte colony-stimulating factor receptor. J Immunol 2005, I 74:7| II-7|22.

24. Rehli M, Lichanska A, Cassady Al, Ostrowski MC, Hume DA: TFEC is a macrophage-restricted member of the microphthalmiaTFE subfamily of basic helix-loop-helix leucine zipper transcription factors. J Immunol 1999, 162:1559-1565.

25. Altin JG, Sloan EK: The role of CD45 and CD45-associated molecules in T cell activation. Immunol Cell Biol I997, 75:430-445.

26. Coughlin SR: Thrombin signalling and protease-activated receptors. Nature 2000, 407:258-264.

27. Gerson SL: MGMT: its role in cancer aetiology and cancer therapeutics. Nat Rev Cancer 2004, 4:296-307.

28. Hoogeveen AT, Rossetti S, Stoyanova V, Schonkeren J, Fenaroli A Schiaffonati L, Van Unen L, Sacchi N: The transcriptional corepressor MTGI6a contains a novel nucleolar targeting sequence deranged in $\mathrm{t}(16 ; 21)$-positive myeloid malignancies. Oncogene 2002, 21:6703-6712.

29. Jenuwein T, Allis CD: Translating the histone code. Science 200I, 293: 1074-1080.

30. Berger SL: Histone modifications in transcriptional regulation. Curr Opin Genet Dev 2002, I 2:142-148.

31. Peterson CL, Laniel MA: Histones and histone modifications. Curr Biol 2004, I4:R546-5I.

32. Fuks F: DNA methylation and histone modifications: teaming up to silence genes. Curr Opin Genet Dev 2005, I5:490-495.

33. Burgers WA, Fuks F, Kouzarides T: DNA methyltransferases get connected to chromatin. Trends Genet 2002, 18:275-277.

34. Takai $D$, Jones PA: The CpG island searcher: a new WWW resource. In Silico Biol 2003, 3:235-240.

35. Iwakuma T, Shiraishi A, Fukuhara M, Kawate H, Sekiguchi M: Organization and expression of the mouse gene for DNA repair methyltransferase. DNA Cell Biol 1996, 15:863-872.

36. Kouzarides $\mathrm{T}$ : Histone methylation in transcriptional control. Curr Opin Genet Dev 2002, I 2:198-209.

37. Bistulfi G, Pozzi S, Ren M, Rossetti S, Sacchi N: A repressive epigenetic domino effect confers susceptibility to breast epithelial cell transformation: implications for predicting breast cancer risk. Cancer Res 2006, 66:10308-10314.

38. Pozzi S, Rossetti S, Bistulfi G, Sacchi N: RAR-mediated epigenetic control of the cytochrome P450 Cyp26al in embryocarcinoma cells. Oncogene 2006, 25: I 400-I 407

39. Galm O, Wilop S, Luders C, Jost E, Gehbauer G, Herman JG, Osieka R: Clinical implications of aberrant DNA methylation patterns in acute myelogenous leukemia. Ann Hematol 2005, 84 Suppl 13:39-46.

40. Esteller M, Herman JG: Generating mutations but providing chemosensitivity: the role of O6-methylguanine DNA methyltransferase in human cancer. Oncogene 2004, 23: I-8.

4I. Alcalay M, Meani N, Gelmetti V, Fantozzi A, Fagioli M, Orleth A, Riganelli D, Sebastiani C, Cappelli E, Casciari C, Sciurpi MT, Mariano AR, Minardi SP, Luzi L, Muller H, Di Fiore PP, Frosina G, Pelicci PG: Acute myeloid leukemia fusion proteins deregulate genes involved in stem cell maintenance and DNA repair. J Clin Invest 2003, I I2:175|-I76I.

42. Dunne J, Cullmann C, Ritter M, Soria NM, Drescher B, Debernardi S, Skoulakis S, Hartmann O, Krause M, Krauter J, Neubauer A, Young BD, Heidenreich O: siRNA-mediated AMLI/MTG8 depletion affects differentiation and proliferation-associated gene expression in $\mathbf{t}(\mathbf{8} ; \mathbf{2} \mathrm{I})$-positive cell lines and primary AML blasts. Oncogene 2006, 25:6067-6078.

43. Shimada H, Ichikawa H, Nakamura S, Katsu R, Iwasa M, Kitabayashi I, Ohki M: Analysis of genes under the downstream control of the $t(8 ; 2 I)$ fusion protein AMLI-MTG8: overexpression of the TISI Ib (ERF-I, cMGI) gene induces myeloid cell proliferation in response to G-CSF. Blood 2000, 96:655-663.

44. Shimada $H$, Ichikawa $H$, Ohki M: Potential involvement of the AMLI-MTG8 fusion protein in the granulocytic maturation characteristic of the $t(8 ; 2 I)$ acute myelogenous leukemia revealed by microarray analysis. Leukemia 2002, 16:874-885.

45. Di Croce L, Raker VA, Corsaro M, Fazi F, Fanelli M, Faretta M, Fuks F, Lo Coco F, Kouzarides T, Nervi C, Minucci S, Pelicci PG: Methyltransferase recruitment and DNA hypermethylation of target promoters by an oncogenic transcription factor. Science 2002, 295: 1079-1082

46. Bailey TL, Elkan C: Fitting a mixture model by expectation maximization to discover motifs in biopolymers. Proc Int Conf Intell Syst Mol Biol 1994, 2:28-36.

47. Herman JG, Graff JR, Myohanen S, Nelkin BD, Baylin SB: Methylation-specific PCR: a novel PCR assay for methylation status of CpG islands. Proc Natl Acad Sci U S A 1996, 93:982I-9826.

Publish with Biomed Central and every scientist can read your work free of charge

"BioMed Central will be the most significant development for disseminating the results of biomedical research in our lifetime. "

Sir Paul Nurse, Cancer Research UK

Your research papers will be:

- available free of charge to the entire biomedical community

- peer reviewed and published immediately upon acceptance

- cited in PubMed and archived on PubMed Central

- yours - you keep the copyright 